\title{
Self-reports on mental processes: A response to Birnbaum and Stegner
}

\author{
SUE DOE NIHM \\ Chang Ri Law University
}

(Michael H. Birnbaum, sponsor)

This paper identifies ideal conditions for proving that people lack self-insight: Ask people in a between-subjects design (with deception) to identify the experimenter's manipulation. Because people fail to identify the variable manipulated, we conclude that they do not understand the causes of their own behavior.

Birnbaum and Stegner (1981) criticized Nisbett and Wilson (1977), arguing that under some circumstances, self-reports correlate with judgments, and therefore that people do have insight into the determinants of their behavior. However, Birnbaum and Stegner's research was conducted using procedures that are too much modeled on the physical sciences to be taken seriously as indications of how people behave in the real world. I have personally conducted two studies that more closely parallel Nisbett and Wilson's original research, conducted in a field setting, in order to determine the situations in which people do or do not know the determinants of their own behavior.

\section{THE “STOCKINGS-PURCHASING” STUDY}

Nisbett and Wilson (1977) in one experiment asked subjects in a department store to choose which of several pairs of nylon stockings on a store counter they preferred. Although the stockings were objectively of equal quality, the pair on the right side of the counter was chosen most often. However, no subject, when asked later, reported that he or she chose the stockings because they were on the right side of the counter. Rather, the subjects mentioned quite irrelevant reasons, such as the fact that the stockings were soft, etc.

To replicate these findings in a realistic situation in which subjects were actually committed to their decisions, I conducted a study in two stores that were exactly alike except that one store had stockings for sale and the other did not. Subjects were observed making purchases through a one-way mirror located unobtru-

Sponsor's note: In 1980, this paper was accepted for publication in Journal of Experimental Social Psychology by the journal's editor, who wrote that it gave him more pleasure to accept this paper than any other he had accepted as editor. However, the publisher made the unusual decision to override the editor, and the paper was not published. Inasmuch as this paper criticizes my own work, I disagree with the conclusions, but $I$ have agreed to sponsor it because I believe that both sides should be heard on this matter.

Sponsor's mailing address: Department of Psychology, University of Illinois, Champaign, IL 61820. sively in each store. Significantly more stockings were sold at the store that had stockings for sale $(t=2.12$, $\mathrm{p}<.06)$. This shows that the true cause of subjects' stocking purchases was the availability of stockings in the store.

However, when asked why they purchased stockings, not one subject gave the true cause of his or her behavior. Instead, the subjects offered socially acceptable but irrelevant explanations such as "I needed stockings," "These stockings were a good buy for the price," etc.

These data clearly confirm Nisbett and Wilson's (1977) conclusion that people do not know the true causes of their behavior. Not one person was able to identify the right reason for buying the stockings (i.e., "because they were there"). However, these results prove that the true cause of purchases is not position, as Nisbett and Wilson suggested, but rather presence in the store.

\section{“IMPORTANCE" JUDGMENT STUDIES}

Nisbett and Wilson (1977) also discussed an experiment in which some subjects read a passage from a novel containing a vivid description of one of the protagonists, whereas others read the same passage with this description deleted. Both groups later judged the emotional impact of the passages. These judgments were the same, regardless of whether the vivid description was present or not. However, subjects who read the vivid description stated that this description increased their judgments of the impact of the overall passage. Nisbett and Wilson concluded that subjects not only are unaware of the factors that actually affect their behavior, but also think that factors affect their behavior when in fact such factors do not.

My own research leads me to draw similar conclusions. In one study, I asked two groups of subjects to judge the heaviness of a milk carton containing milk. One group received a carton that was almost full; the other group got the same carton with two glasses of milk removed. Both groups rated their cartons "slightly heavy" (3.8 and 4.5 on a 6-point scale). The difference was nonsignificant $(\mathrm{t}=1.97, \mathrm{p}>.08)$, indicating that 
judgments of heaviness are unaffected by weight. However, those in the full condition insisted that the extra milk was important to their judgment and made a difference. These data were also found consistent with Nihm's (1976) law.

In a second study, I administered a new type of vitamin pill to a large number of persons over a 2 -month period. A control group did not receive this pill. I then determined whether persons got colds and, if so, how long the colds lasted. In fact, the pill had no significant effect; the frequency and duration of colds were no different among subjects who received the pills and those who did not $(\mathrm{t}=1.37, \mathrm{p}>.10)$. However, when I asked the experimental subjects whether the pill had been effective, only one-third of them said it had no effect. One-third said that the pill had helped them, and the remaining one-third said it had been harmful. Thus, the majority of the experimental subjects believed the pill had had an effect, whereas in fact it had had none.

Birnbaum (personal communication) criticized my conclusion that these experiments indicate that subjects have no insight into the determinants of their behavior. In a reanalysis of my data from the third study, he found that subjects who reported that the pill had helped them had colds that lasted a shorter period of time than their usual colds, whereas those who reported that the pill had harmed them had longer and more frequent colds while on the pill. Birnbaum argued that subjects in the experimental group did not have enough information to evaluate the pill's effect for philosophical rather than psychological reasons. That is, they did not know how long their colds would have lasted without the pill, and so they compared the duration of their colds during the experiment with memories of colds in the past. More generally, Birnbaum contended that, in between-subjects designs such as ours, subjects are unable to make the comparisons required for judgment. With respect to the heaviness study, Birnbaum said that the subjects who were asked to rate the effect of the extra milk are in a within-subjects design, whereas relativity of judgment confounds comparison of judgments between groups. In the "stocking-purchasing" study, he thought we should have told the subjects about the other store and then asked them if they would have purchased stockings in the store that had no stockings.

His argument obviously missed the point. If we told subjects about the control condition, there would have been an implicit "demand" to use this control condition as a basis for comparison, and thus subjects might have drawn the same conclusion as the experimenter. It is obviously vital in these studies to prevent the subjects from having the same information as the experimenter. Only when the subjects' task is to infer the variable manipulated by the experimenter can we expect to prove that the experimenter has more insight into the causes of subjects' behavior than do the subjects.

I might mention that several readers of this paper have been very critical of my research, indicating that these ideas, although exciting and thought-provoking, were not soundly supported by data. However, they have told me not to worry about this, since counterintuitive or speculative ideas are typically regarded by social psychologists as more important and valuable than data. Therefore, I am confident that my paper will have an important influence and that Birnbaum and Stegner's (1981) conclusions and their arguments concerning the measurement of subjective "importance" will not be paid any attention.

\section{REFERENCES}

Birnbaum, M. H., \& Stegner, S. E. (1981). Measuring the importance of cues in judgment for individuals: Subjective theories of IQ as a function of heredity and environment. Journal of Experimental Social Psychology, 17, 159-182.

Ninм, S. D. (1976). Polynomial law of sensation. American Psychologist, 31, 808-809.

NisBetT, R. E., \& Wilson, T. D. (1977). Telling more than we can know: Verbal reports on mental processes. Psychological Review, 84, 231-259.

(Manuscript received for publication March 26, 1984.) 